Nota

\title{
PLOIDIA E FERTILIDADE DE PÓLEN EM PROGÊNIES DE CITROS $\left(^{1}\right)$
}

\author{
EDUARDO CESAR BRUGNARA $\left({ }^{2,4}\right)$; MARIA TERESA SCHIFINO-WITTMANN $\left({ }^{3,4}\right)$; \\ ROBERTO LUIS WEILER $\left({ }^{2,5}\right)$; SERGIO FRANCISCO SCHWARZ $\left(2^{*}\right)$
}

\begin{abstract}
RESUMO
Este trabalho foi desenvolvido para estimar a fertilidade do pólen e determinar o nível de ploidia em progênies dos cruzamentos da tangerineira 'Montenegrina' (C. deliciosa Ten.) com a tangerineira 'King' (C. nobilis Lour.) e com a laranjeira 'Caipira' (C. sinensis (L.) Osb.). As plantas, de pés-francos e com idade entre 11 e 12 anos, são mantidas na Estação Experimental Agronômica da Universidade Federal do Rio Grande do Sul, em Eldorado do Sul. Avaliaram-se o nível de ploidia, através da contagem dos cromossomos em células em meiose, e a fertilidade do pólen, por coloração do pólen com carmim propiônico, em 2005 e 2006. Todos os híbridos avaliados são diplóides e a fertilidade de pólen variou de zero a $98 \%$. C27 - híbrido de 'Montenegrina' x 'Caipira' - revelou-se praticamente estéril, e a fertilidade de C21, do mesmo cruzamento, é de $10 \%$. A menor fertilidade observada no cruzamento da 'Montenegrina' $x$ 'King' foi de $42 \%$.
\end{abstract}

Palavras-chave: Citrus sp., número cromossômico, melhoramento genético, tangerineiras.

\section{ABSTRACT \\ PLOIDY AND POLLEN FERTILITY IN CITRUS HYBRIDS}

This work was performed to estimate pollen fertility and determinate the ploidy level of 11 to 12 years old progenies of crosses of 'Montenegrina' mandarin (Citrus deliciosa Ten.) with 'King' mandarin (C. nobilis Lour.) and with 'Caipira' sweet orange (C. sinensis (L.) Osb.) maintained at Estação Experimental Agronômica of UFRGS, in Eldorado do Sul, Brazil. The ploidy level was determined by chromosome countings in meiosis cells and pollen fertility evaluated by staining pollen grains with propionic carmine. All evaluated hybrids are diploid and pollen fertility varied from zero to $98 \%$. C27, a hybrid 'Montenegrina' x 'Caipira', was found is sterile, and C21, from the same cross, showed $10 \%$ fertility. The lowest observed fertility in the progeny 'Montenegrina' $x$ 'King' was $42 \%$.

Key words: Citrus sp., chromosome number, breeding, mandarin.

$\left({ }^{1}\right)$ Parte da dissertação de Mestrado do primeiro autor. Recebido para publicação em 11 de abril de 2007 e aceito em 10 de dezembro de 2007.

$\left({ }^{2}\right)$ Departamento de Horticultura e Silvicultura, Faculdade de Agronomia, Universidade Federal do Rio Grande do Sul. Av. Bento Gonçalves, 7712, 91540-000 Porto Alegre. E-mail: schwarz@ufrgs.br $\left(^{*}\right)$ Autor correspondente.

$\left({ }^{3}\right)$ Departamento de Plantas Forrageiras e Agrometeorologia, Faculdade de Agronomia, Universidade Federal do Rio Grande do Sul Porto Alegre. E-mail: mtschif@ufrgs.br

$\left({ }^{4}\right)$ Bolsista CNPq.

$\left({ }^{5}\right)$ Bolsista CAPES. 


\section{Introdução}

Em citros, a reprodução sexuada pode ocorrer associada à assexuada, posto que nas sementes de muitas espécies há a formação de embriões sexuais e apomíticos nucelares concomitantemente. Entretanto, para que ocorra a formação de sementes é necessária a fecundação dos núcleos polares por um dos núcleos generativos do grão de pólen, formando o endosperma (Koltunow et al., 1995).

Apesar dos crescentes avanços em biotecnologia que permitem a transformação genética e a hibridação somática, a hibridação convencional tem importante papel na recombinação e introgressão de genes. Programas de melhoramento de citros que visem a variedades produtoras de frutos com pouca ou nenhuma semente contam com duas estratégias principais: obtenção de plantas com baixa viabilidade de pólen ou triplóides.

A viabilidade do pólen de citros é variável entre espécies e variedades (Soost e Roose, 1996), mas dentro da mesma planta ou entre plantas da mesma variedade ocorrem pequenas variações (MOREIRA e GURGEL, 1941). A infertilidade masculina ocorre em laranjeiras, tangerineiras, pomeleiros e limoeiros, muitas vezes causando ausência de sementes nos frutos. A maioria das tangerineiras tem pólen funcional, mas muitos híbridos são inférteis (MoREIRA e Gurgel, 1941; Soost e Roose, 1996; Cavalcante et al, 2000; WeILER, 2006).

As plantas do gênero Citrus e outros gêneros relacionados, normalmente, são diplóides e têm número de cromossomos $2 n$ igual a 18. (Soost e Roose, 1996; Yамамото e Tominaga, 2003). Tetraplóides ocorrem de forma espontânea devido à duplicação de cromossomos durante a embriogênese somática, a qual não tem causa conhecida, mas podem ter origem híbrida (LeE, 1988; Soost e Roose, 1996). Triplóides podem ser obtidos de cruzamentos entre diplóides pela não redução do número cromossômico durante a meiose ou em cruzamentos entre diplóides e tetraplóides (KRUG e BACCHI, 1943; LeE, 1988; Soost e Roose, 1996). Triplóides naturais são sempre de origem zigótica e ocorrem em menor freqüência. Plantas triplóides produzem variável quantidade de frutos, e esses frutos não possuem semente, o que é muito desejável agronomicamente (Soost e Roose, 1996).

Este trabalho foi desenvolvido para estimar a fertilidade do pólen e determinar o número cromossômico em duas progênies dos cruzamentos da tangerineira 'Montenegrina' com a tangerineira 'King' e com a laranjeira 'Caipira'.

\section{Material e Métodos}

As plantas avaliadas neste trabalho, de pésfrancos e com 11 a 12 anos de idade, pertencem às populações de híbridos de tangerineira 'Montenegrina' (C. deliciosa Ten.) x tangerineira 'King' (C. nobilis Lour.) (híbridos MK) e tangerineira 'Montenegrina' x laranjeira 'Caipira' (C. sinensis (L.) Osb.) (híbridos MC), e são mantidas no campo na Estação Experimental Agronômica da Universidade Federal do Rio Grande do Sul, Eldorado do Sul (RS). Botões florais foram coletados em setembro de $2005 \mathrm{e}$ agosto a setembro de 2006. Para contagem de cromossomos, coletaram-se botões com 2,5 a $4 \mathrm{~mm}$ de diâmetro e para análise do pólen, botões em préabertura. O material foi fixado em solução de etanol:ácido acético $3: 1$ por 24 horas e, após, armazenado em etanol $70 \%$ a cerca de $4{ }^{\circ} \mathrm{C}$ até a confecção das lâminas (CAVAlCANTE et al. 2000).

A contagem de cromossomos foi feita macerando-se as anteras cortadas ao meio em uma gota de carmim propiônico 0,6 \% sobre uma lâmina de microscopia, e observada em microscópio com aumentos de 400 e 1.000 vezes. O número cromossômico foi determinado em, no mínimo, cinco células em meiose, nas fases de diacinese ou metáfases, anáfases e telófases I e II.

Para avaliação da fertilidade do pólen, foram utilizados botões florais fechados de tamanho semelhante àqueles em abertura a fim de garantir que se estava analisando pólen maduro. Lâminas foram preparadas macerando-se levemente as anteras de um botão floral em carmim propiônico $0,6 \%$ (totalizando quatro botões por planta, exceto para o híbrido C20, do qual foram avaliados seis botões). As lâminas foram observadas em aumento de 40x, observando-se no mínimo 250 grãos de pólen de cada botão e classificando-os em corados e não corados. Grãos parcialmente corados (Figura 1) foram considerados não corados. Ainda, para certificar-se de que o pólen não corado era inviável e não imaturo, as contagens que resultaram em baixa percentagem de pólen corado foram repetidas em flores abertas.

\section{Resultados e Discussão}

Em todas as plantas analisadas (Tabela 1) observaram células-mãe de pólen com nove bivalentes (Figura 1) e/ou células em telófases e anáfases com nove cromossomos em cada pólo, indicando que são diplóides $(2 n=2 x=18)$. A ocorrência de poliplóides em populações de origem sexual é em geral baixa (Soost e Roose, 1996). Grãos de pólen gigantes, possíveis indicadores de gametas não reduzidos, foram 
observados nos genitores tangerineira 'Montenegrina' e laranjeira 'Caipira', porém em freqüências menores que $0,1 \%$. Em populações pequenas, como as quais a que se dedicou este trabalho, a chance de se notar pelo menos um poliplóide originado pela fusão de gametas não reduzidos é também pequena.

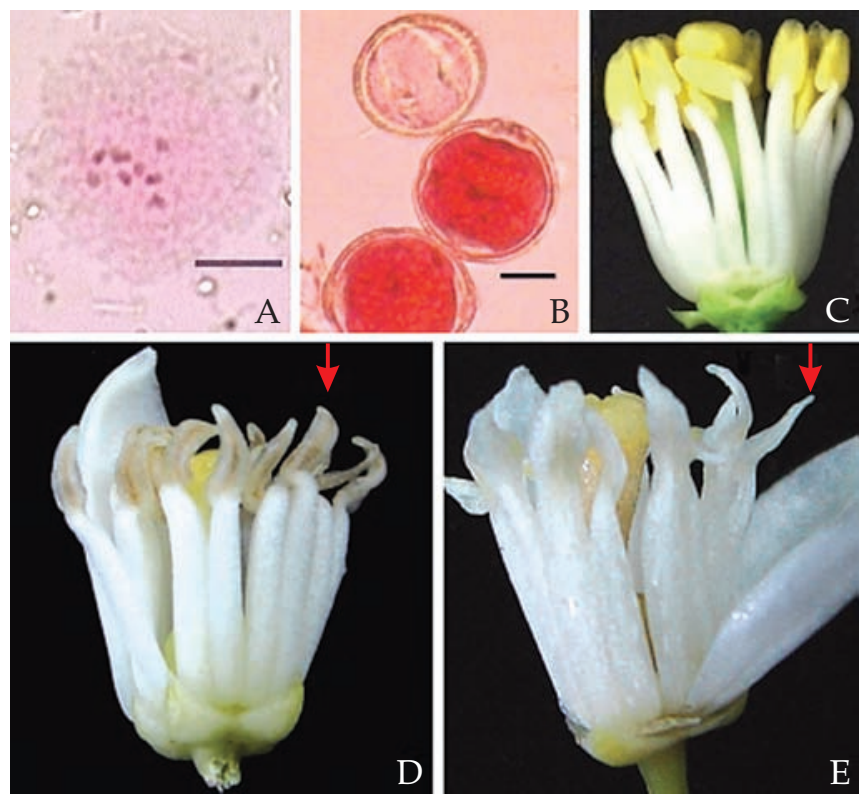

Figura 1. (A) Prófase I no híbrido C25 apresentando 9 bivalentes (escala: $10 \mu \mathrm{m}$ ); (B) Grãos de pólen corados e parcialmente corados (superior) do híbrido D29; (C) Flor da tangerineira 'Montenegrina' com anteras de coloração normal; flores dos híbridos C27 (D) e C20 (E) com anteras de coloração anormal (setas vermelhas), indicando baixa fertilidade masculina. Eldorado do Sul (RS), 2005/2006.
Em espécies do gênero Actinidia (ao qual pertence o kiwizeiro, A. deliciosa), YAN et al. (1997) não observaram nenhum poliplóide em cruzamento entre duas plantas diplóides produtoras de gametas 2n. Já GERACI et al. (1975) obtiveram triplóides do cruzamento entre dois diplóides do gênero Citrus e atribuíram o efeito a gametas femininos não-reduzidos.

Quanto à fertilidade do pólen, foram avaliados 21 híbridos de tangerineira 'Montenegrina' $x$ tangerineira 'King' e 10 híbridos de tangerineira 'Montenegrina' x laranjeira 'Caipira' (Tabela 1). A maioria das plantas proporcionou mais de $70 \%$ de pólen corado, e C26 (MK) atingiu 98\% de viabilidade estimada, sugerindo que estas possuem boa fertilidade masculina. Já o híbrido C08 (MK) atingiu 42\% do pólen corado e foi o menos fértil dentre os híbridos de 'Montenegrina' x 'King'. Avaliações feitas em flores abertas confirmaram as observações em botões em préabertura.

WeILER (2006) observou fertilidade acima de $70 \%$ em todos os 52 híbridos de tangerineira 'Clementina Fina' $x$ tangerineira 'Montenegrina'; Moreira e Gurgel (1941) observaram fertilidade de pólen acima de $60 \%$ em tangerineiras 'Cravo', 'Rio' e 'Temple', enquanto em satsuma 'Owari' houve baixa fertilidade masculina.

Cavalcante et al. (2000) observaram em híbridos de polinização aberta do tangeleiro 'Lee' variação de $9 \%$ a $98 \%$ na fertilidade do pólen medida por coloração com carmim propiônico, com predomínio de plantas com mais de $80 \%$ de fertilidade de pólen.

Tabela 1. Fertilidade do pólen (FP) e nível de ploidia (P) de híbridos da tangerineira 'Montenegrina' com tangerineira 'King' (MK) e 'Montenegrina' com laranjeira 'Caipira' (MC). Eldorado do Sul, RS, 2005/06.

\begin{tabular}{|c|c|c|c|c|c|c|c|c|}
\hline \multicolumn{6}{|c|}{ Híbridos MK } & \multicolumn{3}{|c|}{ Híbridos MC } \\
\hline Híbrido & $\mathrm{FP}^{*}$ & $\mathrm{P}$ & Híbrido & $\mathrm{FP}$ & $\mathrm{P}$ & Híbrido & FP & $\mathrm{P}$ \\
\hline & $\%$ & & & $\%$ & & & $\%$ & \\
\hline C08 & $42 \pm 11,1$ & $2 x$ & D22 & $85 \pm 1,9$ & $2 x$ & $\mathrm{C} 27$ & Nula & $2 x$ \\
\hline D06 & $62 \pm 5,9$ & $2 x$ & D18 & $85 \pm 11,4$ & $2 x$ & C20 & $10 \pm 14,2$ & $2 x$ \\
\hline D32 & $65 \pm 8,0$ & $2 x$ & C10 & $87 \pm 5,9$ & $2 x$ & $\mathrm{C} 21$ & $59 \pm 1,6$ & $2 x$ \\
\hline C07 & $68 \pm 4,3$ & $2 x$ & $\mathrm{C} 23$ & $92 \pm 3,9$ & nd & C11 & $62 \pm 5,9$ & $2 x$ \\
\hline D09 & $70 \pm 2,7$ & $2 x$ & D16 & $94 \pm 4,3$ & $2 x$ & D12 & $73 \pm 8,2$ & $2 x$ \\
\hline C32 & $70 \pm 1,3$ & $2 x$ & $\mathrm{C} 05$ & $95 \pm 4,5$ & $2 x$ & C13 & $75 \pm 4,8$ & $2 x$ \\
\hline D25 & $75 \pm 1,0$ & $2 x$ & $\mathrm{C} 01$ & $96 \pm 2,5$ & nd & C31 & $81 \pm 7,2$ & $2 x$ \\
\hline D03 & $79 \pm 2,9$ & $2 x$ & D08 & $97 \pm 3,0$ & $2 x$ & D10 & $88 \pm 3,7$ & $2 x$ \\
\hline C17 & $80 \pm 9,8$ & $2 x$ & D21 & $97 \pm 2,1$ & $2 x$ & C09 & $90 \pm 2,5$ & $2 x$ \\
\hline D29 & $81 \pm 4,7$ & $2 x$ & $\mathrm{C} 26$ & $98 \pm 1,7$ & $2 x$ & $\mathrm{C} 25$ & $95 \pm 3,5$ & $2 x$ \\
\hline C22 & $83 \pm 8,4$ & nd & - & - & - & - & - & - \\
\hline Montenegrina & $58 \pm 6,8$ & - & King & $79 \pm 6,8$ & - & Caipira & $47 \pm 8,6$ & - \\
\hline
\end{tabular}

* Média \pm semi-amplitude do intervalo de confiança $95 \%$.

nd $=$ não determinado. 
Os híbridos de tangerineira 'Montenegrina' com laranjeira 'Caipira' proporcionaram maior variação na fertilidade de pólen. No híbrido C20, observaram-se em média $10 \%$ de pólen corado, e em um dos botões avaliados houve $42 \%$ de pólen corado e os outros cinco, de $1 \%$ a $6 \%$. Esse fato sugere um efeito genético interagindo com um efeito do ambiente. As anteras dessa planta são esbranquiçadas (Figura 1), com exceção daquele botão mais fértil que teve algumas anteras amareladas. Quanto à planta C27, as quatro lâminas confeccionadas continham pouco ou nenhum grão de pólen, e praticamente todos não corados, o que indica ser a planta praticamente androestéril. As anteras deste híbrido são de coloração parda (Figura 1).

Frost e SoOst (1968) afirmam que anteras brancas ou creme-pálidas não contém pólen, o que confirma as observações feitas nos híbridos C20 e C27. Esses autores apresentaram como exemplo a laranjeira de umbigo 'Baía' (C. sinensis), na qual ocorre esterilidade masculina, da mesma forma que em outras variedades de laranjeira de umbigo, formando anteras esbranquiçadas. O abortamento de anteras em citros parece estar relacionado com interações entre genes citoplasmáticos e nucleares (VARDI e SPIEGEL-RoY, 1988), mas não há relatos do fenômeno envolvendo citoplasma de tangerineiras da espécie $C$. deliciosa Ten.

Na laranjeira 'Caipira Comum', avaliada por Domingues et al. (1999), observou-se viabilidade de pólen de $78,2 \%$, superior à constatada neste trabalho, provavelmente por efeito do ambiente ou mesmo por efeito genético, já que podem existir diferenças entre clones de um cultivar (Domingues et al., 2000). Baixa fertilidade masculina também foi observada por Domingues et al. (1999; 2000) e LATAdo et al. (2004), em C. sinensis, e por Cavalcante et al. (2000), em híbridos de polinização aberta do tangeleiro 'Lee'.

\section{Agradecimento}

Os autores agradecem à Fundação de Amparo à Pesquisa do Estado Rio Grande do Sul pelo apoio financeiro, à Coordenação de Aperfeiçoamento de Pessoal de Nível Superior (CAPES) e ao Conselho Nacional de Desenvolvimento Científico e Tecnológico (CNPq) pelas bolsas concedidas.

\section{Referências}

CAVALCANTE, H.C.; SCHIFINO-WITTMANN, M.T.; DORNELLES, A.L.C. Meiotic behavior end pollen fertility in an open-pollinated population of 'Lee' mandarin [Citrus clementina $\times(C$. paradisi $\times$ C. tangerina)]. Scientia Horticulturae, Amsterdan, v.86, p.103-114, 2000.
DOMINGUES, E.T.; TULMANN NETO, A.; TEÓFILO SOBRINHO, J. Viabilidade do pólen em variedades de laranja doce. Scientia Agricola, Piracicaba, v.56, n.2, p. 265-272, 1999.

DOMINGUES, E.T.; TULMANN NETO, A.; TEÓFILO SOBRINHO, J. Viabilidade de pólen de laranja Pêra e outras variedades assemelhadas. Ciência Rural, Santa Maria, v.30, n.1, p.85-89, 2000.

FROST, H.B.; SOOST, R.K. Seed Reproduction: Development of Gametes and Embryos. In: REUTHER, W.; BATCHELOR, L.D.; WEBBER, H.J. (Ed.). The Citrus Industry, Volume II. Revised Edition. Oakland, Caliornia: University of California, 1968. p.290-324.

GERACI, G.; ESEN, A.; SOOST, R.K. Triploid progenies from $2 \mathrm{x} \times 2 \mathrm{x}$ crosses of Citrus cultivars. Journal of Heredity, Washington, v.66, p.177-178, 1975.

KOLTUNOW, A.M.; SOLTYUS, K.; NITO, N.; McCLURE, S. Anther, ovule, seed and nucellar embrio development in Citrus sinensis cv. Valencia. Canadian Journal of Botany, Otawa, v.73, 1567-1582, 1995.

KRUG, C.A.; BACCHI, O. Triploid varieties of citrus. Journal of Heredity, Washington, v.34, p.277-283, 1943.

LATADO, R.R.; BUENO FILHO, J.S.S.; POMPEU JUNIOR, J.; TULMANN NETO, A. Correlações entre viabilidade de pólen e características de frutos em mutantes de laranjeira 'Pêra'. Pesquisa Agropecuária Brasileira, Brasília, v.39, n.10, p.961-965, 2004.

LEE, L.S. Citrus polyploidy - origins and potential for cultivar improvement. Australian Journal of Agricultural Research, Victoria, v.39. p.735-747, 1988.

MOREIRA, S.; GURGEL, J.T.A. A fertilidade de pólen e sua correlação com o número de sementes, em espécies e formas do gênero Citrus. Bragantia, Campinas, v.1, n.11-12, p.669-711, 1941.

SOOST, R.K.; ROOSE, M.L. Citrus. In: JANICK, J.; MOORE, J.N. Fruit breeding. Volume I: tree and tropical fruits. New York: J. Wiley, 1996. p.257-323.

VARDI, A.; SPIEGEL-ROY, P.A. A new approach to selection for seedlessness. In: INTERNATIONAL CITRUS CONGRESS MIDDLE EAST, 6., 1988, Tel Aviv. Proceedings... Tel Aviv: International Society of Citriculture, 1988. v.1, p.131-136, 1988.

WEILER, R. Caracterização morfológica, citogenética e molecular de uma população de tangerineiras híbridas de 'Clementina Fina' (Citrus clementina Hort. ex. Tan.) e 'Montenegrina' (C. deliciosa Ten.). 2006. 67f. Dissertação (Mestrado) - Programa de Pós-Graduação em Fitotecnia, Faculdade de Agronomia, Universidade Federal do Rio Grande do Sul, Porto Alegre, 2006.

YAMAMOTO, M.; TOMINAGA, S. High chromosomal variability of mandarins (Citrus spp.) revealed by CMA banding. Euphytica, Wageningen, v.129, n.3, p.267-274, 2003.

YAN, G.; FERGUSON, A.R.; McNEILAGE, M.A. Numerically unreduced (2n) gametes and sexual polyploidization in Actinidia. Euphytica, Wageningen, v.96, p.267-272, 1997. 